\title{
ESTIMATION OF FUEL LOSS AND SPATIAL-TEMPORAL DISPERSION OF VEHICULAR POLLUTANTS AT A SIGNALIZED INTERSECTION IN DELHI CITY, INDIA
}

\author{
RAJNI DHYANI, NIRAJ SHARMA \& MUKTI ADVANI \\ Transport Planning and Environment Division, CSIR-Central Road Research Institute, India
}

\begin{abstract}
Vehicular traffic is considered one of the major contributors to urban air pollution in a city like Delhi. Signalized traffic intersections are considered as urban hotspots due to their high air pollution levels which generally exceed the air quality standards specified by the regulatory agencies. The high air pollution levels mainly result from the idling of a large number of motor vehicles at these signalized intersections resulting in fuel losses and corresponding emissions leading to deteriorating air quality. There are $\sim 950$ signalized traffic intersections in Delhi city. A large number of the population works and lives close to these traffic intersections and are exposed to these air pollutants. Therefore, it becomes imperative to understand the spatial-temporal distribution of vehicular emissions resulting because of the idling of motor vehicles at these intersections. In the present study, the fuel loss estimation due to the idling of vehicles was carried out at Lodhi Road intersection using idling fuel consumption data carried out on various test vehicles representing the Delhi traffic. The fuel loss was converted into emissions using fuel-based Intergovernmental Panel on Climate Change (IPCC) emission factors. The emissions have been estimated in terms of greenhouse gas $\left(\mathrm{CO}_{2}, \mathrm{CH}_{4}\right.$, and $\left.\mathrm{N}_{2} \mathrm{O}\right)$ emissions and indirect greenhouse gas $\left(\mathrm{CO}, \mathrm{NO}_{\mathrm{x}}\right.$, and $\left.\mathrm{NMVOC}\right)$. The results indicated that daily there was $\sim 230$ litre of petrol, $\sim 100$ litre of diesel and $\sim 170 \mathrm{~kg}$ of compressed natural gas (CNG) loss due to idling at Lodhi Road intersection. The resultant emissions load estimated was $\sim 1300 \mathrm{~kg}$ of $\mathrm{CO}_{2}, 13 \mathrm{~kg}$ of $\mathrm{NO}_{x}, 90 \mathrm{~kg}$ of $\mathrm{CO}$ per day. The spatial extent of vehicular pollutant has been assessed with the help of the CAL3QHC model.
\end{abstract}

Keywords: emissions, fuel loss, idling, signalized intersection, CAL3QHC model.

\section{INTRODUCTION}

The traffic intersections are considered as air quality hotspot because of generally poor air quality at these places which often exceeds the stipulated air quality standards. The main reasons for this is high vehicular traffic activities, vehicular idling due to traffic delay, red time signal etc. A vehicle run on a city road trip consists of idling, acceleration, cruise, and deceleration modes [1]. The share of these different stages depends upon driver behaviour, level of traffic congestion at traffic intersections etc. Further, the fuel consumption of vehicles depends upon factors viz. type and category of vehicles, engine technology, inspection and maintenance (I \& M) practices etc along with the driving cycle of the city [2], [3]. Large variations in traffic flows, increased queuing time and constricted road geometries makes signalized road intersections as pollution hotspots [4], [5]. The delays at traffic intersections result in idling fuel losses and corresponding emissions which deteriorate the air quality of surrounding areas. A study carried out by Sharma et al. [6] estimated idling fuel losses at 950 signalized traffic intersections in Delhi to be $\sim 262,703 \mathrm{~kL}$ petrol, $\sim 145,284 \mathrm{~kL}$ diesel, $248 \mathrm{kt} \mathrm{CNG}$ and 10,202 kL LPG per year. Further, if these losses converted into monetary terms they estimated to be around 5.9 billion USD per year ( 1 US $\$=70$ Indian Rs.).

The people working, commuting or spending time at these signalized traffic intersections gets exposed to high level of air pollutants. Complexity in dispersion of air pollution at urban intersection makes it difficult to manage air quality at these hotspots. Thus, to manage the air 
quality at these urban hotspots, it becomes more important to understand the extent of spread and dispersion behaviour of pollutant at traffic intersections. The dispersion of air pollutants at traffic intersections get influenced by various factors viz. intersection geometry, surface roughness, wind speed and wind direction etc.. Vehicular pollution dispersion models have been used to predict present and future air quality along the roads/highways. They have been used and have helped in improving the understanding of the pollution dispersion at traffic intersections. There are many line source models (AERMOD, CALINE4, and ADMS) which have been used regularly to predict air quality along road/highway corridors modelling. In the present study, Gaussian equation based CAL3QHC model have been used predict the air quality at a selected traffic intersection. CAL3QHC is an exclusive traffic intersection/ hotspot model. The model has been used in various studies to predict air quality at traffic intersections, however, very few studies have been carried out in India at traffic intersections as well as using this model.

Thus, in the present study, authors have attempted an indicative exercise to estimate emissions due to the idling of vehicles at a signalized intersection in Delhi city. Further, spatial-temporal extent of the vehicular pollution (under mixed traffic conditions) at Lodhi Road intersections has been assessed with help of Gaussian based CAL3QHC intersection model.

\section{METHODOLOGY}

Delhi city has been experiencing exponential growth in the motorized vehicle population from $\sim 4.3$ million in the year 2005 to nearly 10 million vehicles in 2016 [7]. Delhi registered vehicles constitutes nearly $4.22 \%$ of the vehicular population of India [8]. Road transport is the main mode of transportation in the city. There are $\sim 950$ signalized traffic intersections in Delhi which could be divided into high ( $>0.2$ million vehicles/day), medium (0.1-0.2 million vehicles/day) and low ( $<0.1$ million vehicles/day) traffic intersections according to their traffic volume. The private mode of transportation viz., car, and two-wheelers constitutes $\sim 85 \%$ of all traffic volume of Delhi city. Delhi has the highest traffic density, therefore regular traffic congestion and delays at various traffic intersections are not unfamiliar in the city. The selected signalized traffic intersection is located at Lodhi Road $\left(28^{\circ} 35^{\prime} 28.06^{\prime \prime} \mathrm{N}\right.$, $77^{\circ} 13^{\prime} 44.24^{\prime \prime E}$ ) at an elevation of 707 feet (Fig. 1). Lodhi road intersection is a low capacity intersection $(<0.1$ million vehicles/day) with an average daily traffic volume of $\sim 92,000$ vehicles. The Lodhi road intersection is located in a mix of government offices, schools, colleges and residential complexes. However, the surroundings of selected site are relatively greener, spacious and have planned development as compared to most of the Delhi city.

\subsection{Estimation of idling fuel losses and corresponding emissions}

The methodology for estimation of fuel loss and corresponding emissions at Lodhi Road signalized intersection consists of two parts: (i) carrying out fuel consumption studies at idling on various test vehicles (representatives of vehicles fleet plying on selected city/state). These tests simulate and help in estimating the fuel consumed during idling of vehicles at various signalized intersections; and (ii) converting the fuel losses as estimated in step (i) into emissions by employing appropriate emission factors and various other input parameters collected from primary surveys or secondary sources.

For the estimation of idling fuel consumption, different categories and vintage of (twowheelers, bike scooters, cars, etc.) petrol-powered and diesel-powered vehicles were tested [6], [9]. The vehicles tested were broadly categorized in the following categories: (i) $2 \mathrm{~W}-4 \mathrm{~S}$ 


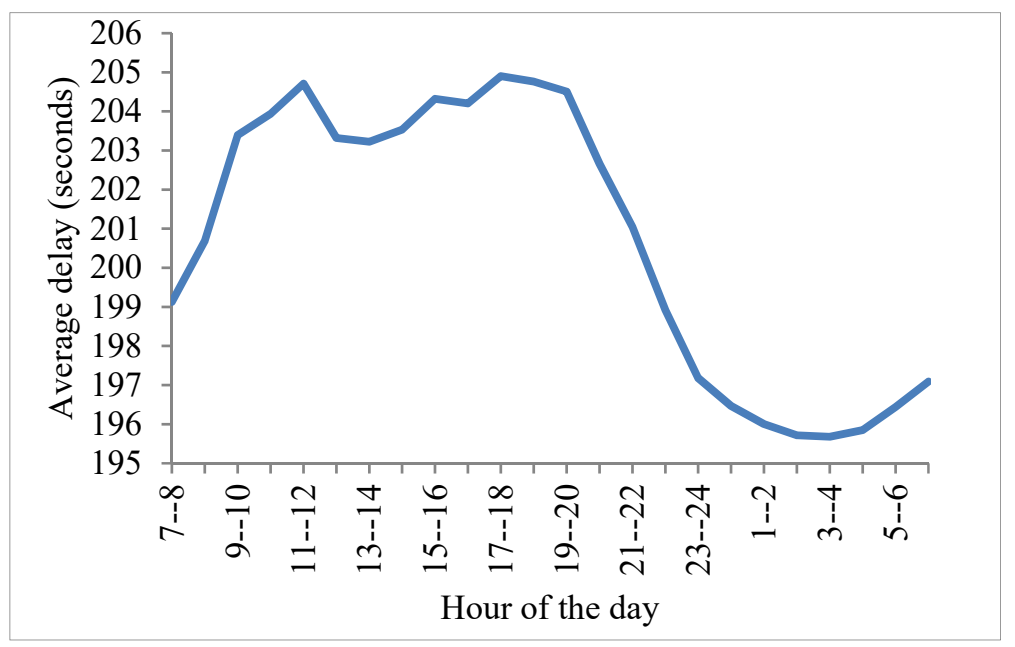

Figure 1: Average delay at Lodhi Road signalized traffic intersection.

(two wheelers-4 stroke-motorcycle); (ii) car-petrol; (iii) car-diesel; (iv) LCV (light commercial vehicles)-diesel; and (v) bus-diesel, HCV (heavy commercial vehicles), 3W (three wheelers)-auto, which form the fleet composition in Delhi.

The total number of vehicles idling at selected intersection due to delay has been estimated by cumulative input-output flow polygon approach [10] are shown in Table 1. From Table 1 , maximum idling traffic could be observed during evening hours (17.00-18.00 and 18.0019.00 hours).

Further, the maximum waiting time could be observed during morning and evening traffic peak hours. During late night hours, traffic delay was observed to be less as compared to day time hours due to low traffic count at intersection (Fig. 1).

Idling fuel consumption was estimated in terms of mass units $(\mathrm{kg})$ then converted in terms of equivalent energy units by applying the fuel specific net calorific values (NCV) for emission estimations (TJ/t). Idling emissions (kg/hour) were estimated using IPCC [11], [12] default pollutant-specific $\left(\mathrm{CO}_{2}, \mathrm{CH}_{4}, \mathrm{CO}, \mathrm{N}_{2} \mathrm{O}, \mathrm{NO}_{\mathrm{x}}\right.$ and NMVOC) emission factors (kg/TJ) for each fuel type used [13]. The detailed methodology for estimation of idling fuel consumption and corresponding emissions can be referred from [6].

\subsection{CAL3QHC model description}

CAL3QHC is a Gaussian based mathematical model to predict vehicular pollutants viz., Carbon monoxide (CO) or other inert pollutant from vehicular at traffic intersections. CAL3QHC is a consolidation of the CALINE3 line source dispersion model and an algorithm that estimates the length of the queues formed by idling vehicles at signalized intersections [14]. The model predicts the air pollution concentrations from both moving and idling vehicles. CAL3QHC requires all input parameters necessary to run CALINE4, on addition to these input idling emission rates, number of moving lanes, approach traffic volume at each link, idling emission factors signal cycle length, red time signal, clearance lost time, Saturation flow rate, signal type, and arrival type etc. at the intersection is required. Table 2 presents the input parameters collected/estimated for air quality prediction by CAL3QHC model at Lodhi Road intersection. 
Table 1: Hourly idling traffic at Lodhi Road signalized intersection.

\begin{tabular}{|c|c|c|c|c|c|c|}
\hline Time & Car & 2 W-4S & Auto rickshaw (3W) & Bus & LCV & HCV \\
\hline $7-8$ & 274 & 136 & 94 & 24 & 18 & 0 \\
\hline $8-9$ & 394 & 203 & 148 & 21 & 13 & 1 \\
\hline $9-10$ & 555 & 338 & 234 & 42 & 17 & 0 \\
\hline $10-11$ & 628 & 367 & 255 & 31 & 14 & 0 \\
\hline $11-12$ & 654 & 369 & 325 & 25 & 32 & 1 \\
\hline $12-13$ & 602 & 299 & 255 & 23 & 22 & 1 \\
\hline $13-14$ & 596 & 304 & 246 & 22 & 22 & 2 \\
\hline $14-15$ & 612 & 311 & 275 & 14 & 20 & 0 \\
\hline $15-16$ & 642 & 373 & 298 & 15 & 23 & 1 \\
\hline $16-17$ & 664 & 358 & 269 & 17 & 24 & 0 \\
\hline $17-18$ & 758 & 365 & 260 & 23 & 20 & 1 \\
\hline $18-19$ & 756 & 366 & 256 & 21 & 12 & 0 \\
\hline $19-20$ & 671 & 394 & 262 & 12 & 27 & 0 \\
\hline $20-21$ & 564 & 291 & 205 & 18 & 16 & 1 \\
\hline $21-22$ & 455 & 238 & 149 & 11 & 14 & 0 \\
\hline $22-23$ & 338 & 109 & 73 & 10 & 12 & 4 \\
\hline $23-24$ & 171 & 50 & 49 & 5 & 9 & 3 \\
\hline $24-1$ & 99 & 29 & 39 & 0 & 6 & 4 \\
\hline $1-2$ & 61 & 16 & 21 & 1 & 4 & 3 \\
\hline $2-3$ & 30 & 16 & 10 & 0 & 3 & 3 \\
\hline $3-4$ & 27 & 10 & 12 & 0 & 5 & 3 \\
\hline $4-5$ & 31 & 13 & 28 & 1 & 5 & 5 \\
\hline $5-6$ & 84 & 29 & 39 & 9 & 5 & 7 \\
\hline $6-7$ & 135 & 53 & 54 & 14 & 6 & 1 \\
\hline Total & 9800 & 5035 & 3855 & 357 & 348 & 42 \\
\hline$\%$ share & 50.4 & 25.9 & 19.8 & 1.8 & 1.8 & 0.2 \\
\hline & & & & & & \\
\hline
\end{tabular}

The CAL3QHC model has been used to predict $\mathrm{CO}$ concentration under prevailing traffic and meteorological conditions during morning (10-11 am) and evening (6-7 pm) traffic peak hours. The $\mathrm{CO}$ being the indicator pollutant for vehicular activities was chosen for the present study.

\subsection{Estimation of emission factors}

In the present study, hourly emission factors were estimated for twelve links. Out of twelve links, eight were free flow links and four were idling links. Following methodologies were used to estimate the emission factors for both the cases.

\subsubsection{Free flow traffic emission factors}

The weighted emission factor used in free flow traffic conditions was estimated for the eight links which have free flow conditions. Due to absence of vehicle speed based emission factors, the weighted emission factor (WEF) were estimated on the basis of vehicle kilometre 
Table 2: Input parameters for CAL3QHC model.

\begin{tabular}{|c|c|c|c|}
\hline S. no. & Parameters & Unit/value & Source \\
\hline (i) & CO measurement (hourly) & $\mathrm{mg} / \mathrm{m}^{3}$ or $\mu \mathrm{g} / \mathrm{m}^{3}$ & Secondary [15] \\
\hline \multicolumn{4}{|c|}{ Measurement of fuel consumption and free flow/idling emission factors } \\
\hline (i) & Traffic volume & Vehicles/hour & Primary \\
\hline (ii) & $\begin{array}{l}\text { Categorization of vehicles based on fuel } \\
\text { type (petrol, diesel, CNG, LPG) technology } \\
\text { type ( } 2 \text { strokes, } 4 \text { strokes) }\end{array}$ & No. of vehicles & Primary and secondary \\
\hline (iii) & $\begin{array}{l}\text { Age profile/vintage of vehicle (fuel station } \\
\text { survey) }\end{array}$ & Number or $\%$ & Primary and secondary \\
\hline (iv) & $\begin{array}{l}\text { Fuel consumption by different categories of } \\
\text { vehicles during idling (petrol, diesel, CNG } \\
\text { and LPG vehicles) }\end{array}$ & $\mathrm{ml} / 10 \mathrm{~min}$ & $\begin{array}{c}\text { Primary and secondary } \\
{[9]}\end{array}$ \\
\hline (v) & $\begin{array}{l}\text { Average hourly time delay at intersection } \\
\text { for each category of vehicle }\end{array}$ & Seconds (s) & Primary \\
\hline (vi) & Net calorific value (NCV) & $\mathrm{TJ} / 10^{3}$ tonne & Secondary [11], [12] \\
\hline (vii) & Emission factor (EF) (idling) & tonne/TJ & Secondary [11], [12] \\
\hline (viii) & Emission factor (EF) (free flow traffic) & $\mathrm{g} / \mathrm{km}$ & Secondary [16] \\
\hline \multicolumn{4}{|c|}{ Meteorological data } \\
\hline (i) & Wind speed & $\mathrm{m} / \mathrm{s}$ & Secondary [15] \\
\hline (ii) & Stability class & $\begin{array}{l}\text { Pasquill-Gifford } \\
\text { (P-G) }\end{array}$ & Secondary \\
\hline (iv) & Mixing height & $\mathrm{m}$ & Secondary [17] \\
\hline (v) & Background concentration & $\mathrm{ppm}$ & Primary \\
\hline (vi) & Multiple wind direction & degree $\left(^{\circ}\right)$ & Primary \\
\hline (vii) & Wind direction & degree $\left(^{\circ}\right)$ & Secondary [15] \\
\hline (viii) & Wind direction increment angle & degree $\left(^{\circ}\right)$ & Primary \\
\hline (ix) & Start angle & degree $\left(^{\circ}\right)$ & Primary \\
\hline (x) & End angle & degree $\left(^{\circ}\right)$ & Primary \\
\hline \multicolumn{4}{|c|}{ Road geometry } \\
\hline (i) & Road length & meter $(\mathrm{m})$ & Primary \\
\hline (ii) & Link height & meter $(\mathrm{m})$ & Primary \\
\hline (iii) & Mixing zone width & meter $(\mathrm{m})$ & Primary \\
\hline \multicolumn{4}{|c|}{ Queue parameters } \\
\hline (i) & Average signal cycle length & seconds (s) & Estimated \\
\hline (ii) & Average red time length & seconds (s) & Estimated \\
\hline (iii) & Clearance lost time & seconds (s) & Estimated \\
\hline (iv) & Approach traffic volume & $\begin{array}{l}\text { vehicles per hour } \\
\text { (vph) }\end{array}$ & Primary \\
\hline (v) & Idle emission factor & $\begin{array}{l}\text { gram/vehicle-hour } \\
\text { (g/v-hr) }\end{array}$ & Primary \\
\hline (vi) & Saturation flow rate & $\begin{array}{c}\text { vehicle/hour/lane } \\
(\mathrm{v} / \mathrm{hr} / \text { lane })\end{array}$ & Estimated \\
\hline (vii) & Signal type & $\begin{array}{l}\text { Pre-timed/ } \\
\text { actuated/semi- } \\
\text { actuated }\end{array}$ & Primary \\
\hline (viii) & Arrival type & $\begin{array}{c}\text { Worst/below } \\
\text { average/average/ } \\
\text { above average/ } \\
\text { best progressing }\end{array}$ & Primary (observed) \\
\hline
\end{tabular}


travelled based (VKT) emission factors provided by CPCB [16]. The WEF is a function of vehicle emission factor (vehicle category, type, fuel type, age profile, vintage etc.) and vehicle activity (traffic volume). The equation for calculation of WEF is as follows:

$$
W E F=\left[\sum(j) \sum(k y) \mathrm{N}(\mathrm{j}, \mathrm{ky}) . \mathrm{EF}(\mathrm{i}, \mathrm{j}, \mathrm{ky})\right] / \text { Total no. of vehicles, }
$$

where:

- $W E F$ is weighted emission factor $(\mathrm{g} / \mathrm{km})$;

- $\quad N(j, k y)$ is number of vehicles of a particular type $\mathrm{j}$ and age $\mathrm{k}$ in year $\mathrm{y}$;

- $E F(i, j, k y)$ is emission factor for component $\mathrm{i}$ for the vehicle type $\mathrm{j}$ and age $\mathrm{k}$ in year $\mathrm{y}$ $(\mathrm{g} / \mathrm{km})$

- $\quad i$ is pollutant component (viz. CO);

- $j$ is type of vehicle (i.e. $2 \mathrm{~W}, 3 \mathrm{~W}$ (auto rickshaw), cars, bus, truck etc.);

- $k$ is age of the vehicle in year $y$.

\subsubsection{Idling traffic emission factors}

Idling emission factor for $\mathrm{CO}$ was estimated and expressed in terms of g/vehicle-hour. The following equation has been used for estimation of-emissions during idling by various categories of vehicles (i)

$$
E_{i}=\frac{\left[\sum V_{j(k y)} \cdot F C_{(j, f, k y)} \cdot D_{f} \cdot T_{(J j, f, k y) .} N C V_{f} \cdot E F_{(f, i)}\right]}{3.6} * 10^{6},
$$

where:

- $E_{i}=$ Total emission of pollutants type $i(\mathrm{~kg} / \mathrm{h})$;

- $V_{j(k y)}=$ Vehicle type $j$ of vintage $k y$ (no. of vehicles);

- $\quad F C_{(j, f, k y)}=$ Fuel consumption during idling by vehicle type $j$ using fuel type $f$ of vintage $k y(\mathrm{l} / \mathrm{h})$;

- $D_{f}=$ Density of fuel $f(\mathrm{~kg} / \mathrm{l})$;

- $\quad T_{(j, f, k y)}(\mathrm{s})=$ Time delay at traffic intersections by vehicle type $j$ of fuel type $f$ of vintage ky;

- $\quad N C V_{f}=$ Net calorific value for fuel type $f($ Tera-joule/tonne $(\mathrm{TJ} / \mathrm{kt}))$;

- $E F_{(f, i)}=$ Emission factor for fuel type $f$ of pollutant type $i$ (tonnes/Tera-joule $\left.(\mathrm{t} / \mathrm{TJ})\right)$.

\subsection{Meteorological parameters}

The micro-meteorological data such as wind speed, wind direction was taken from the IMD air quality monitoring station at Lodhi Road [15]. The hourly mixing height values were obtained from the Indian Meteorological Department (IMD) [17]. The worst case wind angle was considered in the present study with 0 degree as start wind angle and 360 as end angle with 5 degree wind increment angle.

Tables 3 and 4 presents the link-wise input data collected/estimated for the prediction of air quality at the selected traffic intersection. Table 3 presents the input used for free flow traffic link and Table 4 presents the input required for the idling traffic/queue links. 
Table 3: Traffic input parameters for free flow traffic links in CAL3QHC model.

\begin{tabular}{|c|c|c|c|c|c|c|c|}
\hline \multirow{2}{*}{ Link } & \multicolumn{2}{|c|}{$\begin{array}{c}\text { No. of vehicles (emission } \\
\text { factor, g/mile) }\end{array}$} & \multicolumn{2}{c|}{ Wind speed (m/s) } & \multicolumn{2}{c|}{ Mixing height (m) } & \multirow{2}{*}{$\begin{array}{c}\text { Mixing zone } \\
\text { width (m) }\end{array}$} \\
\cline { 2 - 6 } & $10-11 \mathrm{am}$ & $6-7 \mathrm{pm}$ & $10-11 \mathrm{am}$ & $6-7 \mathrm{pm}$ & $10-11 \mathrm{am}$ & $6-7 \mathrm{pm}$ & \\
\hline Link 1 & $1557(2)$ & $1563(1.9)$ & 1.1 & 1.3 & 1110 & 1800 & 14 \\
\hline Link 3 & $2112(2)$ & $2130(1.9)$ & 1.1 & 1.3 & 1110 & 1800 & 14 \\
\hline Link 4 & $1729(2)$ & $1738(2)$ & 1.1 & 1.3 & 1110 & 1800 & 14 \\
\hline Link 6 & $1307(2)$ & $1549(2)$ & 1.1 & 1.3 & 1110 & 1800 & 14 \\
\hline Link 7 & $1870(2)$ & $1644(2)$ & 1.1 & 1.3 & 1110 & 1800 & 15 \\
\hline Link 8 & $1388(2.1)$ & $1817(2)$ & 1.1 & 1.3 & 1110 & 1800 & 15 \\
\hline Link 10 & $1388(2.1)$ & $1603(2)$ & 1.1 & 1.3 & 1110 & 1800 & 15 \\
\hline Link 11 & $1388(2)$ & $1603(1.9)$ & 1.1 & 1.3 & 1110 & 1800 & 15 \\
\hline
\end{tabular}

Table 4: Traffic input parameters for idling traffic/queue links in CAL3QHC model.

\begin{tabular}{|l|c|c|c|c|c|c|c|c|}
\hline \multirow{2}{*}{ Input parameters } & \multicolumn{2}{|c|}{ Link 2} & \multicolumn{2}{c|}{ Link 5 } & \multicolumn{2}{c|}{ Link 9 } & \multicolumn{2}{c|}{ Link12 } \\
\cline { 2 - 9 } & $\begin{array}{c}10-11 \\
\mathrm{am}\end{array}$ & $\begin{array}{c}6-7 \\
\mathrm{pm}\end{array}$ & $\begin{array}{c}10-11 \\
\mathrm{am}\end{array}$ & $\begin{array}{c}6-7 \\
\mathrm{pm}\end{array}$ & $\begin{array}{c}10-11 \\
\mathrm{am}\end{array}$ & $6-7 \mathrm{pm}$ & $\begin{array}{c}10-11 \\
\mathrm{am}\end{array}$ & $\begin{array}{c}6-7 \\
\mathrm{pm}\end{array}$ \\
\hline $\begin{array}{l}\text { Average signal } \\
\text { cycle length (s) }\end{array}$ & 281 & 290 & 281 & 290 & 281 & 290 & 281 & 290 \\
\hline Red time cycle (s) & 105 & 107 & 105 & 107 & 105 & 107 & 105 & 107 \\
\hline $\begin{array}{l}\text { Clearance lost time } \\
\text { (s) }\end{array}$ & 3 & 3 & 3 & 3 & 3 & 3 & 3 & 3 \\
\hline $\begin{array}{l}\text { Approach traffic } \\
\text { volume(v/hr) }\end{array}$ & 1201 & 1581 & 1386 & 1381 & 1186 & 1308 & 1373 & 1360 \\
\hline $\begin{array}{l}\text { Idling emission } \\
\text { factor (g/hr-v) }\end{array}$ & 2.4 & 2.3 & 3.4 & 3 & 3.1 & 4 & 3.6 & 4 \\
\hline $\begin{array}{l}\text { Saturation flow } \\
\text { rate (v/hr/lane) }\end{array}$ & 1800 & 1800 & 1800 & 1800 & 1800 & 1800 & 1800 & 1800 \\
\hline
\end{tabular}

\section{RESULTS AND DISCUSSIONS}

\subsection{Idling fuel loss and corresponding emissions}

The fuel consumption during idling at Lodhi road intersection was estimated for different type and categories of vehicles for 24-hour period. Petrol driven vehicles (especially, private vehicles viz. cars and two-wheelers) are predominantly more in Delhi as compared to public and commercial transport vehicles. Therefore, it was observed that among all fuel type, losses of petrol was highest followed by CNG, diesel and LPG (Table 5).

The diurnal variation of idling emissions viz. $\mathrm{NO}_{x}, \mathrm{CO}, \mathrm{N}_{2} \mathrm{O}, \mathrm{CH}_{4}, \mathrm{NMVOC}$, and $\mathrm{CO}_{2}$ has been shown in Fig. 2. Thus, there were idling emission losses to the tune of $\sim 1300 \mathrm{~kg} \mathrm{of} \mathrm{CO}_{2}$, $13 \mathrm{~kg}$ of $\mathrm{NO}_{\mathrm{x}}, 90 \mathrm{~kg}$ of $\mathrm{CO}$ per day. Further, peak idling emissions could be observed during morning and evening peak traffic hours. During night time to early morning hours, when there is less idling traffic at intersection the estimated idling emissions were found to be comparatively very low. 
Table 5: Idling fuel loss at Lodhi Road intersection.

\begin{tabular}{|l|c|}
\hline Idling fuel loss & Quantity (per day) \\
\hline Petrol & $232.14 \mathrm{~L}$ \\
\hline Diesel & $97.8 \mathrm{~L}$ \\
\hline CNG & $169.8 \mathrm{~kg}$ \\
\hline LPG & $10.27 \mathrm{~L}$ \\
\hline
\end{tabular}

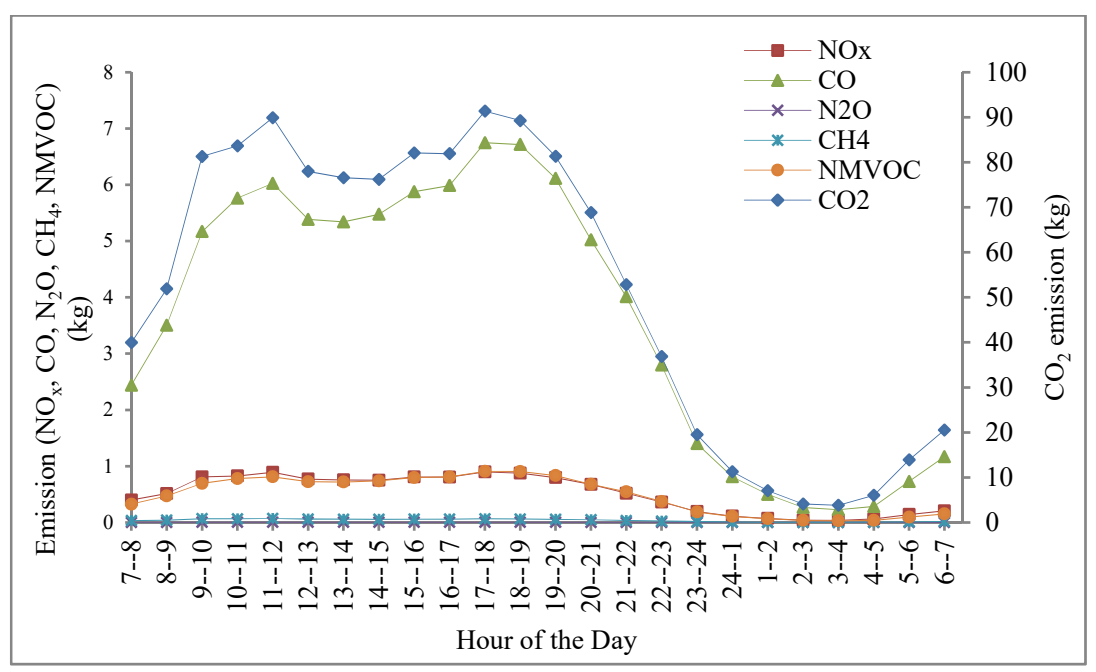

Figure 2: Diurnal variation in idling emissions at Lodhi Road signalized traffic intersection.

\subsection{Spatial-temporal extent of emissions at signalized intersection}

The spatial extent of vehicular pollutant has been assessed with the help of the CAL3QHC model [14]. Like every typical four arm signalized traffic intersection in India, each arm of Lodhi road intersection has three traffic movements - free left, straight and right turn. Out of these three movements, straight and right movement traffic has to idle at intersection (Fig. 3). In the present study, the spatial temporal extent of pollutants has been observed for morning and evening peak hours only.

The CO concentrations were estimated at pre-identified receptors locations at $2 \mathrm{~m}, 5 \mathrm{~m}$ and $10 \mathrm{~m}$ from mixing zone width at its four arms and at centre (middle of intersection). Worst case scenario (in terms of wind angle) selected for the present study and 60 minute average concentration of $\mathrm{CO}$ was predicted. The background concentration (input in model) was kept zero to observe only the vehicular emissions contribution to the surroundings. During morning peak hour (10-11 am) the highest concentration was $343.5 \mu \mathrm{g} / \mathrm{m}^{3}$ $\left(0.34 \mathrm{mg} / \mathrm{m}^{3}\right)$ observed at $2 \mathrm{~m}$ away from mixing zone width, at distance of $10 \mathrm{~m}$ the concentration was zero, indicating absence of contribution from vehicular emission. During the evening peak hour $(6-7 \mathrm{pm})$, the highest $\mathrm{CO}$ concentration was observed at centre of intersection $\left(1030.5 \mu \mathrm{g} / \mathrm{m}^{3}\right.$ or $\left.1.03 \mathrm{mg} / \mathrm{m}^{3}\right)$ followed by $2 \mathrm{~m}\left(687 \mu \mathrm{g} / \mathrm{m}^{3}\right), 10 \mathrm{~m}\left(572.5 \mu \mathrm{g} / \mathrm{m}^{3}\right)$ and $20 \mathrm{~m}\left(343.5 \mu \mathrm{g} / \mathrm{m}^{3}\right)$ away from mixing zone width, thus indicating reduction in vehicular pollution as the distance from the intersection (or zone of influence) increases (Fig. 4). 


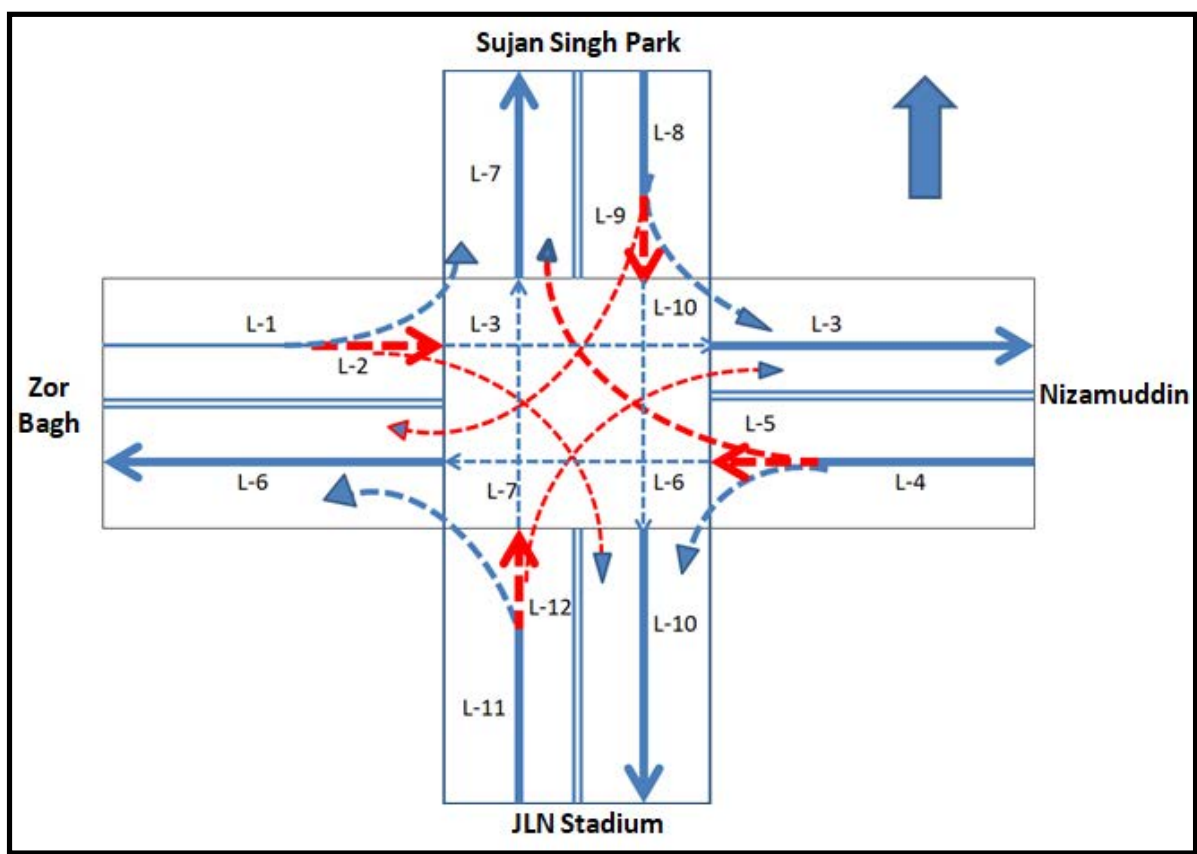

Figure 3: Traffic movement and selected links at Lodhi Road signalized traffic intersection $(\mathrm{L}=$ link $)$.

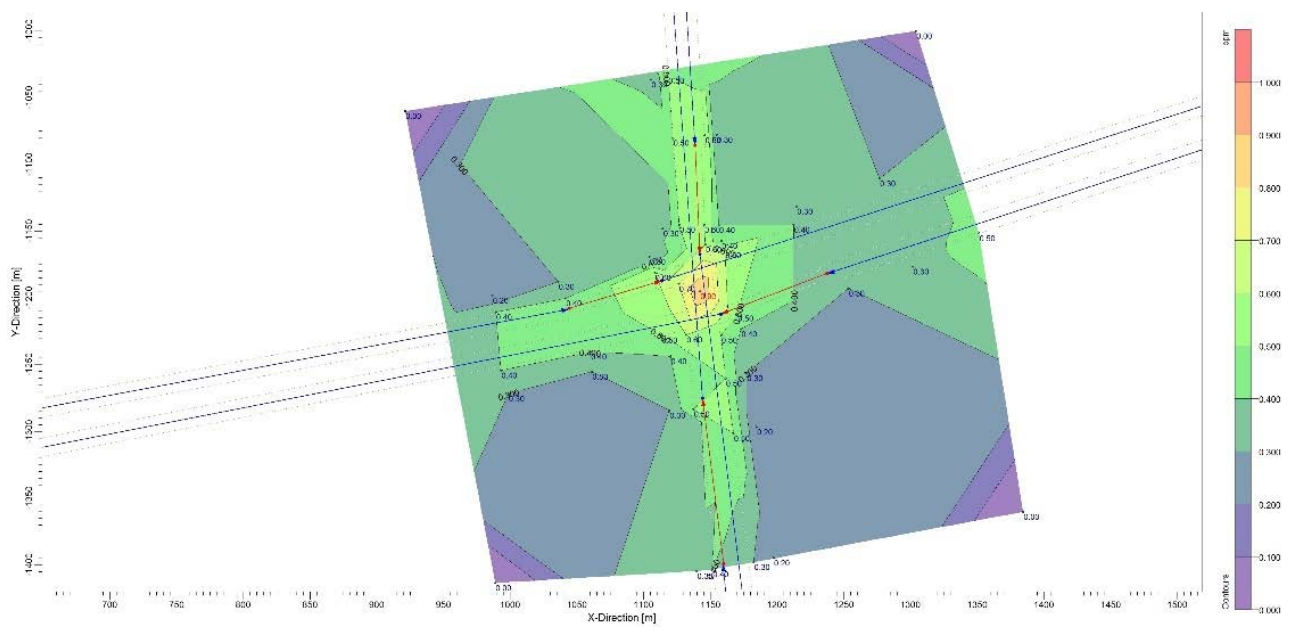

Figure 4: Contour map of CO concentration along Lodhi Road intersection (1800-1900 hours).

During night time (e.g. 2-3 am), due to low traffic volume ( $\sim 70$ vehicles/link/hour), the average signal cycle length ( 72 seconds) and red time signal ( 20 seconds) also get reduced which results in smaller queue length and less idling, thus lower $\mathrm{CO}$ contribution from 
vehicles at intersection. Further, $\sim 100 \mathrm{~m}$ away from intersection during any time of the day, the vehicular pollutant influence was negligible. When compared to the average observed CO concentration $\left(\sim 1.5 \mathrm{mg} / \mathrm{m}^{3}\right)$ during evening hour $(6-7 \mathrm{pm})$ from ambient air quality station at Lodhi Road [15], the performance of the CAL3QHC model was found to be satisfactory.

\section{CONCLUSIONS}

In the present study, idling fuel loss and corresponding emissions were estimated at Lodhi Road intersection in Delhi (India) and an indicative exercise was carried out with the help of CAL3QHC model to understand the spatial and temporal extent of $\mathrm{CO}$ dispersion at the selected intersection. The Lodhi road intersection is low traffic capacity intersection with traffic volume of $\sim 92,000$ vehicles/day; out of these $\sim 19,000$ vehicles idle on an average for $\sim 200$ seconds per hour in a day. Large number of petrol driven vehicles (cars, two-wheelers) results in highest loss of petrol fuel followed by CNG (three-wheelers, buses), Diesel (LCV, $\mathrm{HCV}$ ) and LPG. The fuel loss results corresponding emissions, with highest being $\mathrm{CO}_{2}$ followed by $\mathrm{NO}_{x}, \mathrm{CO}$, etc. The same exercise could be applied at any signalized intersection to get the estimate of fuel loss and related emission throughout the city in order to find out the enormity of the problem.

Apart from estimation of idling fuel losses and corresponding emissions the spatial and temporal distribution of pollutants holds an important aspect in air quality management studies at these intersections. The spatial and temporal dispersion of pollutants delineate the zone of influence, which could help further in drafting the air quality and traffic management plans. Further, it is necessary to understand the dispersion at intersections because of the exposure level and impact on health of people (due to idling emission and resultants poor air quality) who resides, work or pay short visit at intersections/hotspots due to variety of reasons (viz. commuting, business activity, etc.). The CAL3QHC is Gaussian based intersection model which has been used in the present study to predict the $\mathrm{CO}$ concentration. The high concentration observed during the peak hours, (especially during evening peak hours), gives clear indication of the magnitude of contribution of vehicles in deteriorating the air quality in surrounding areas or its influence zone of a traffic intersection. However, the present study is an indicative exercise to present spatial temporal extent of $\mathrm{CO}$ in an urban hotspot using CAL3QHC model. The CAL3QHC model has been used in very few studies in India that too under heterogeneous traffic conditions and owing to unavailability or lack of understanding related to traffic and idling/queue link parameters requirement. Studies that are more comprehensive need to be carried out in future for performance evaluation and validation of CAL3QHC model for Indian traffic (heterogeneous or mixed traffic) and meteorological conditions.

\section{ACKNOWLEDGEMENTS}

The authors are thankful to the Director of CSIR-CRRI for kindly permitting us to publish the present paper. Dr Rajni Dhyani is thankful to CSIR for providing her financial assistance through CSIR-Research Associate fellowship.

\section{REFERENCES}

[1] Goel, R. \& Guttikunda, S.K., Evolution of on-road vehicle exhaust emission in Delhi. Atmospheric Environment, 105, pp. 78-90, 2015.

[2] Ishaque, M. \& Noland, R., Simulated pedestrian travel and exposure to vehicle emissions. Transportation Research Part D, 13(1), pp. 27-46, 2008. 
[3] Pandian, S., Gokhale, S. \& Goshal, A.K., Evaluating effects of traffic and vehicle characteristics on vehicular emissions near traffic intersections. Transportation Research Part D, 14, pp. 180-196, 2009.

[4] Goel, A. \& Kumar, P., Zone of influence for particle number concentrations at signalised traffic intersections. Atmospheric Environment, 123, pp. 25-38, 2015.

[5] Soulhac, L., Garbero, V., Salizzoni, P., Mejean, P. \& Perkins, R., Flow and dispersion in street intersections. Atmospheric Environment, 43, pp. 2981-2996, 2009.

[6] Sharma, N., Kumar, P.V.P., Dhyani, R., Sekhar, C.R. \& Ravinder, K., Idling fuel consumption and of emission of air pollutants at selected signalized intersections in Delhi. Journal of Cleaner Production, 212, pp. 8-12, 2019.

[7] Transport Department, Government of National Capital Territory of Delhi (GNCTD), Total vehicles registered zonewise up to 31 March 2016. http://delhi.gov.in/wps/wcm/ connect/doit_transport/Transport/Home/. Accessed on: 15 Apr. 2017.

[8] Ministry of Road Transport and Highways, Government of India (MoRTH), Road Transport Yearbook (2015-2016). http://morth.nic.in/showfile.asp?lid=3141. Accessed on: 23 May 2017.

[9] Central Road Research Institute (India) (CRRI), Evaluation of economic loss due to idling of vehicles at signalized intersection and mitigation measures (ELSIM), funded under 12th five year plan, 2017.

[10] Kyte, M. \& Tribelhorn, M., Operation, analysis and design of signalized intersection (final report): A module for the introductory course in transportation engineering. Department of Transportation, University Transportation Centers Program, 2014.

[11] Intergovernmental Panel on Climate Change (IPCC), Revised Guidelines for National Greenhouse Gas Inventories, Volume 2 Energy, 1996.

[12] Intergovernmental Panel on Climate Change (IPCC), Guidelines for National Greenhouse Gas Inventories, Work Book Volume 2, 2006.

[13] Singh, A., Gangopadhyay, S., Nanda, P.K., Bhattacharya, C., Sharma, C. \& Bhan, C., Trends of greenhouse gas emission from the road transport sector in India. Science of Total the Environment, 390(1), pp. 124-131, 2008.

[14] User's guide to CAL3QHC version 2.0: A modelling methodology for predicting pollutant concentrations near roadway intersections (revised). EPA-454/R-92-006 (revised). USEPA Office of Air Quality Planning and Standards, Research Triangle Park, NC 27711, September 1995.

[15] Central Pollution Control Board (CPCB), Central control room for air quality management: All India. Average report criteria. https://app.cpcbccr.com/ccr/\#/caaqmdashboard-all/caaqm-landing/data. Accessed on: 10 Mar. 2018.

[16] Central Pollution Control Board (CPCB), Status of pollution generated from road transport in six mega cities. Ministry of Environment Forest and Climate Change, Government of India. http://cpcb.nic.in/cpcbold/upload/NewItems/NewItem_215_ Report. pp. 127-137, 2015.

[17] Attri, S.D., Singh, S., Mukhopadhyay, B. \& Bhatnagar, A.K., Atlas of hourly mixing height and assimilative capacity of atmosphere in India. Met. Monograph No. Environment Meteorology-01/2008, Indian Meteorological Department, Government of India: New Delhi, 2008. 